\title{
Airway obstruction in competitive swimmers
}

\author{
Marja Päivinen $^{1,2}$, Tuula Putus ${ }^{3}$, Pentti Kalliokoski ${ }^{4}$, Heikki Tikkanen ${ }^{1,2}$ \\ ${ }^{1}$ Department of Sports and Exercise Medicine, Institute of Clinical Medicine, University of Helsinki, Helsinki, Finland; \\ marja.paivinen@hula.fi \\ ${ }^{2}$ Foundation for Sports and Exercise Medicine, Helsinki, Finland \\ ${ }^{3}$ University of Turku, Turku, Finland \\ ${ }^{4}$ Department of Environmental Sciences, University of Eastern Finland, Kuopio, Finland
}

Received 20 January 2013; revised 21 February 2013; accepted 28 February 2013

\section{ABSTRACT}

Background: Swimming has been shown to cause beneficial effects on lung function. However, increased adverse effects have been hypothesized due to the air quality of indoor swimming pools. Objectives: To compare competitive swimmers present lung function to swimmers twenty to thirty years ago and examine the associations between lung function and medical history and reported respiratory symptoms in present swimmers. Methods: One hundred swimmers, 47 females and 53 males were studied with flow-volume spirometry. These findings were compared with ones obtained 20 - 30 years ago among 98 swimmers, 40 females and 58 males. Forced expiratory volume in one second $\left(F E V_{1}\right)$, forced expiratory volume (FVC) and their ratio (FEV\%) were analysed for airways obstruction. Associations between lung function and asthma, allergy, and respiratory symptoms were examined using questionnaire. In addition airways inflammation was measured with exhaled nitric oxide measurement $\left(\mathrm{FE}_{\mathrm{NO}}\right)$ in present swimmers. Airborne trichloramine was measured in air of indoor swimming pools. Results: Airway obstruction was found in 15\%, 15 out of 100 studied swimmers, which all reported physician diagnosed asthma and/or family history of asthma. Most, 12 out of 15 of swimmers with obstruction finding, were males. Twenty to thirty years ago obstruction was found in $\mathbf{1 7}$ of the $\mathbf{9 8}$ swimmers. Airborne concentrations of trichloramine in the present swimming pools, were low, less than 0.1 $\mathrm{mg} / \mathrm{m}^{3}$. Conclusion: Airway obstruction was associated with asthma and family history of asthma. There was no increase in obstruction findings among competitive swimmers within 2 - 3 decades. Measured concentrations of trichloramine raised no concern on swimmers health.
Keywords: Pulmonary Function Tests; Obstruction; Asthma; Allergy; Symptoms; Swimming

\section{INTRODUCTION}

Prevalence of asthma and respiratory problems among endurance athletes and especially among competitive swimmers has been suggested to be increased within last decades [1]. However, beneficial effects of swimming training; improvement of lung function and relief of respiratory symptoms in asthmatics have been reported [2-6]. Swimming has also been recommended physical exercise for asthmatics, because of its low asthmogenity. Swimming triggers fewer respiratory symptoms than running or cycling at same intensity level [7].

Competitive swimmers have high training amounts and increased minute ventilation during their training. Higher than predicted lung volumes and capacities has been observed in competitive swimmers [8,9]. However, competitive swimmers are exposed to the indoor swimming pool air by the water disinfection by-products, especially trichloramine, which has been suggested to be harmful for respiratory health [10-12].

The aim of this study was to examine if obstruction findings are increased among competitive swimmers within two to three decades by measuring spirometry in present competitive swimmers and comparing the findings with the competitive swimmers 20 to 30 years ago. Secondary aim was to examine the associations between spirometry findings and asthma, allergies, respiratory symptoms and airways inflammation in present swimmers, and to examine environmental conditions by measuring trichloramine concentrations of indoor swimming pool air.

\section{METHODS}

One hundred present competitive swimmers, $(\mathrm{N}=$ 100), 47 women and 53 men, with mean age of 17 (SD 3) years, were studied with questionnaire and pulmonary function measurements. Flow-volume spirometry and 
exhaled nitric oxide $\left(\mathrm{FE}_{\mathrm{NO}}\right)$ were measured. Swimmers mean training history was 9 (SD 4) years and training frequency for 7 (SD 3) times per week which is 14 hours (SD 6) of training per week.

Spirometry findings from 20 - 30 years ago of 98 competitive swimmers, 40 females and 58 males, with mean age of 14 (SD 2) years, were examined.

Forced vital capacity FVC and forced expiratory volume in one second $\left(\mathrm{FEV}_{1}\right)$ and their ratio $\mathrm{FEV} \%$ were analysed. All studied swimmers were non smokers. Spirometry findings of present competitive swimmers were compared with findings in competitive swimmers 20 - 30 years ago.

Present swimmers filled structured questionnaire which consisted questions about basic information, training history, allergies, asthma, family history of asthma, family history of allergies and respiratory symptoms during swimming training. Same questionnaire has been used in earlier studies in competitive swimmers [13,14].

Flow-volume spirometry was measured with Spiro Star 2000 spirometer (Medikro Finland) according to the ATS and ERS guidelines [15]. Spirometry results were expressed as percent of personal age, size and sex matched predicted values. Airways obstruction finding was confirmed when FVC or $\mathrm{FEV}_{1}$ were less than $79 \%$ or $\mathrm{FEV} \%$ was less than $87 \%$ of predicted values for Finnish population [16] or for Finnish children under 18 years [17] according to the ATS and ERS criteria [18, 19].

Exhaled nitric oxide measurements $\left(\mathrm{FE}_{\mathrm{NO}}\right)$ were performed with hand-held Niox Mino (Aerocrine Sweden) analyzer. Method has been suggested to be suitable for studying environmental effect for airways in indoor swimming pools $[20,21]$. $\mathrm{FE}_{\mathrm{NO}}$ results were presented as concentration, parts per billion (ppb) of nitric oxide in exhaled air.

Concentrations of airborne trichloramine by the indoor pools were determined with the method described by Hery et al. [22]. Trichloramine is collected onto impregnated quartz filter, reduced to chloride and analyzed by ion chromatography.

T-test was used for comparing the groups. First, the normality of data was studied with Shapiro-Wilk test. If it failed the rank sum Mann-Whitley test was performed.

All comparison analyses were performed with SigmaPlot software 11.0. Systat Software, inc. San Jose CA. USA.

The Ethics committee of The Hospital district of Helsinki and Uusimaa approved the study protocol.

\section{RESULTS}

Airway obstruction was found in $15 \%$ of the swimmers. All of them reported asthma or family history of asthma. Almost all, 12 out of 15 swimmers with obstruction finding were men (Table 1).

Mean (SD) FVC was 111 (13) \%, FEV 1 was 111 (14) $\%$, and their ratio FEV\% was 97 (9) \% and peak expiratory flow PEF was 106 (14) \% of predicted. Percents of predicted were significantly higher in present swimmers than in swimmers 20 - 30 years ago (Table 3 ).

Findings of airway obstruction did not associate with reported respiratory symptoms or elevated $\mathrm{FE}_{\mathrm{NO}}$ level in swimmers. However, FEV\% was significantly lower and $\mathrm{FE}_{\mathrm{NO}}$ were significantly higher in non-symptomatic swimmers than in symptomatic swimmers (Table 4).

The airborne concentrations of trichloramine were low,

Table 1. Demographics of 100 competitive swimmers, 85 swimmers with normal spirometry and 15 swimmers with airway obstruction finding.

\begin{tabular}{|c|c|c|c|c|c|c|}
\hline & \multicolumn{3}{|c|}{ Normal $\mathrm{N}=85$} & \multicolumn{3}{|c|}{ Obstruction $\mathrm{N}=15$} \\
\hline & All $\mathrm{N}=85$ & Women $\mathrm{N}=44$ & Men $\mathrm{N}=41$ & All $\mathrm{N}=15$ & Women $\mathrm{N}=3$ & Men $\mathrm{N}=12$ \\
\hline Physician diagnosed allergy & $23 / 85$ & $9 / 44$ & $14 / 41$ & $7 / 15$ & $1 / 3$ & $6 / 12$ \\
\hline Physician diagnosed asthma & $7 / 85$ & $6 / 44$ & $1 / 41$ & $9 / 15$ & $2 / 3$ & $7 / 12$ \\
\hline Family history of physician diagnosed allergy & $47 / 85$ & $22 / 44$ & $25 / 41$ & $11 / 15$ & $3 / 3$ & $8 / 12$ \\
\hline Family history of physician diagnosed asthma & $17 / 85$ & $8 / 44$ & $9 / 41$ & $9 / 15$ & $3 / 3$ & $6 / 12$ \\
\hline Respiratory symptoms in swimming & $37 / 85$ & $22 / 44$ & $15 / 41$ & $9 / 15$ & $2 / 3$ & $7 / 12$ \\
\hline $\mathrm{FE}_{\mathrm{NO}}$ level $^{*}$ & $13.9(11)$ & $12(8)$ & $15.3(13)$ & $16(12)$ & $16(6)$ & $17(12)$ \\
\hline BMI kg/m² & $20.9(2)$ & $20.1(2)$ & $21.8(2)$ & $22.9(2)$ & $21.6(2)$ & $23.2(2)$ \\
\hline Height cm & $174(10)$ & $168(6)$ & $181(9)$ & $179(7)$ & $175(3)$ & $179(8)$ \\
\hline Weight kg & $64(12)$ & $57(7)$ & $72(10)$ & $74(7)$ & $66(8)$ & $75(7)$ \\
\hline Age years & $16(3)$ & $16(2)$ & $17(3)$ & $18(2)$ & $17(1)$ & $18(2)$ \\
\hline Training history years & $8(4)$ & $8(3)$ & $8(5)$ & $11(2)$ & $10(3)$ & $11(2)$ \\
\hline Weekly trainings & $7(3)$ & $7(2)$ & $6(3)$ & $10(3)$ & $10(5)$ & $10(2)$ \\
\hline
\end{tabular}

${ }^{*}$ with normal spirometry $\mathrm{FE}_{\mathrm{NO}}$ was measured successfully in 73 out of 85 swimmers; 39 out of 44 women and of the men 34 out of 41 . All of the swimmers with obstruction finding were measured. 
Table 2. Airway obstruction findings in present competitive swimmers and in competitive swimmers 20 - 30 years ago.

\begin{tabular}{ccc}
\hline Spirometry finding & $\begin{array}{c}\text { Present swimmers } \\
\mathrm{N}=100 \\
\mathrm{M} 53 / \mathrm{N} 47\end{array}$ & $\begin{array}{c}\text { Swimmers 20 - } \\
30 \text { years ago } \\
\mathrm{N}=98 \\
\mathrm{M} \mathrm{58/N} \mathrm{40}\end{array}$ \\
\hline Normal & $85 / 100$ & $81 / 98$ \\
$\begin{array}{c}\text { Obstruction criteria } \\
\text { FEV1/FVC or } \\
\text { FEV }_{1} / \text { VC }<\text { 88\% of } \\
\text { predicted }\end{array}$ & $15 / 100$ & $17 / 98^{\S}$ \\
\hline
\end{tabular}

$\overline{\S^{\S} \text { Four swimmers had obstruction finding (65\% - 79\% of predicted) in FVC, }}$ $\mathrm{FEV}_{1}$ or both.

Table 3. Spirometry findings, age and BMI in present swimmers and in swimmers 20 - 30 years ago (FVC, FEV 1 and FEV\% presented as percent of size, age and sex predicted values).

\begin{tabular}{cccc}
\hline & $\begin{array}{c}\text { Present swimmers } \\
\mathrm{N}=100 \\
\mathrm{M} 53 / \mathrm{N} 47\end{array}$ & $\begin{array}{c}\text { Swimmers 20 - 30 } \\
\text { years ago N = 98 } \\
\text { M 58/N 40 }\end{array}$ & P-value \\
\hline Age (years) & $17(3)$ & $14(2)$ & $\mathrm{P}<0.001^{*}$ \\
BMI & $21(2)$ & $19(2)$ & $\mathrm{P}<0.001^{*}$ \\
FEV \% & $85(7)$ & $82(8)$ & $\mathrm{P}=0.125$ \\
FVC (\%) & $111(13)$ & $99(13)$ & $\mathrm{P}<0.001^{*}$ \\
FEV $_{1}(\%)$ & $111(14)$ & $107(19)$ & $\mathrm{P}<0.001^{*}$ \\
FEV \% (\%) $^{\text {(1) }}$ & $97(9)$ & $93(9)$ & $\mathrm{P}=0.002^{*}$ \\
\hline
\end{tabular}

${ }^{\S}$ ratio of FVC and $\mathrm{FEV}_{1},{ }^{*}$ Significant difference.

Table 4. Spirometry findings and $\mathrm{FE}_{\mathrm{NO}}$ result in present swimmers with respiratory symptoms and without. Spirometry results are presented as percent of predicted.

\begin{tabular}{cccc}
\hline & $\begin{array}{c}\text { No Respiratory } \\
\text { symptoms } \\
\mathrm{N}=54 \\
\text { mean (SD) }\end{array}$ & $\begin{array}{c}\text { Respiratory } \\
\text { symptoms } \\
\mathrm{N}=46 \\
\text { mean (SD) }\end{array}$ & P-value \\
\hline FVC & $110(13)$ & $113(13)$ & $\mathrm{P}=0.236^{\mathrm{ns}}$ \\
FEV 1 & $109(13)$ & $107(15)$ & $\mathrm{P}=0.661^{\mathrm{ns}}$ \\
FEV\% & $99(8)$ & $95(9)$ & $\mathrm{P}=0.014^{*}$ \\
PEF & $103(15)$ & $99(14)$ & $\mathrm{P}=0.200^{\mathrm{ns}}$ \\
MEF 50 & $101(26)$ & $94(25)$ & $\mathrm{P}=0.149^{\mathrm{ns}}$ \\
$\mathrm{FE}_{\mathrm{NO}}(\mathrm{ppb})$ & $14(19)$ & $19(14)$ & $\mathrm{P}=0.001^{*}$ \\
\hline
\end{tabular}

*Significant difference, ${ }^{\text {ns }}$ No significant difference.

less than $0.1 \mathrm{mg} / \mathrm{m}^{3}$, in the indoor swimming pools the competitive swimmers trained.

\section{DISCUSSION}

Prevalence of airway obstruction was $15 \%$ in the studied 100 swimmers which was not higher than in swimmers measured 20 - 30 years ago. This finding is contrary to the suggestions of respiratory problems being increased in endurance athletes especially in swimmers within the last decades [1].

Spirometric values FVC, $\mathrm{FEV}_{1}$, and PEF were approximately $110 \%$ of the individual predicted value. This is consistent with the study of Magel and Faulgner 1967 and suggests that swimming training may have beneficial effects on lung function [23].

Mean FEV\% was $97 \%$ of predicted level suggesting airway obstruction in the group of swimmers. FEV\% result in the studied swimmers, as a ratio of FVC and $\mathrm{FEV}_{1}$, may be a sign of the typical increased lung volume in swimmers which is believed to be developed as a result of repetitive rapid inhalation near TLC during swimming [24].

Results of FVC, $\mathrm{FEV}_{1}, \mathrm{FEV} \%$ presented as percent of size, age and sex predicted values in studied competitive swimmers were significantly better than in competitive swimmers 20 - 30 years ago. Therefore, it can be concluded, that there was no decrease of lung function in competitive swimmers over 2 - 3 decades.

All of the present swimmers with obstruction finding in spirometry had asthma or family history of asthma. Obstruction findings did not associate with reported respiratory symptoms which is consistent to previous studies of Rundell et al. in elite athletes [25,26].

There were many swimmers with obstruction finding, who did not report respiratory symptoms. This may be explained by the phenomenon of "Poor perceivers" of asthma, which has been introduced in previous studies [26-29]. Some athletes may not recognise the symptoms of airways obstruction, because the changes in pulmonary function in pulmonary disease develop slowly.

Almost all of the obstructive swimmers (13 out of 15) were men. That may be linked to the obtained gender differences in previous studies. Half of the males with airway obstruction did not report symptoms at all. In recent study of competitive swimmers [14] there was found significant difference in reported symptoms between female and male swimmers. Females reported significantly more symptoms and also during lower intensity swimming than males [14]. Results may suggest that females with lung function problem may have more symptoms during swimming and therefore may search for medical help and sufficient medication earlier than males.

Differences in symptoms may have also something to do with the body size. The males are bigger in size and reporting fewer symptoms. Interestingly in this study the females with obstruction finding were mean 0.07 meters taller than other female swimmers without obstruction finding (Table 1). The economy of movement during swimming in water related to body size and weight is different than economy of movement on land. Also water environment itself may have an effect on swimmers lung function differently according to size.

There were many swimmers who reported symptoms, 
but had no findings in pulmonary function tests. That may tell that flow-volume spirometry may not be sensitive enough to detect early phase of pulmonary disease which may start in small airways and cause respiratory symptoms: in t-test there was found significant difference in $\mathrm{FEV} \%$ in swimmers who reported respiratory symptoms compared to swimmers not reporting symptoms, suggesting a slight fall in pulmonary function (Table 4) even though it was not enough for obstruction finding. These findings may courage to study the respiratory symptoms and their underlying factors in athletes further with more sensitive pulmonary function testing methods.

A significant difference was also found in exhaled nitric oxide level between swimmers with reported symptoms and without. However normal $\mathrm{FE}_{\mathrm{NO}}$ level, (ppb < 20 ) was found in both groups. This may be a sign of possible protective anti-inflammatory effects of endurance exercise training in swimmers. Endurance training including swimming has been suggested to have anti-inflammatory effects [30,31].

Mean values of $\mathrm{FE}_{\mathrm{NO}}$ were normal in present swimmers which may reflect the possible inflammation protective role of swimming training. Significant differences were found in inflammatory level in $\mathrm{FE}_{\mathrm{NO}}$ and in FEV\% as percent of predicted when swimmers with and without symptoms were compared. As the mean values of $\mathrm{FE}_{\mathrm{NO}}$ were normal in present swimmers, the environmental effect of frequent exposure to indoor swimming pool air does not support any harmful consequences.

The airborne concentrations of trichloramine at the indoor swimming pools the swimmers trained were, less than $0.1 \mathrm{mg} / \mathrm{m}^{3}$, clearly less than $0.5 \mathrm{mg} / \mathrm{m}^{3}$ which is the suggested critical level for respiratory symptoms and which also is the Finnish occupational exposure limit.

According to the findings the lung function in active young Finnish competitive swimmers is the same or even improved over in new generation after 2 - 3 decades. All of swimmers with airway obstruction had asthma or family history of asthma.

\section{REFERENCES}

[1] Arie, S. (2012) What can we learn from asthma in elite athletes? British Medical Journal, 344, Article ID: e2556. doi:10.1136/bmj.e2556

[2] Wicher, I.B., Ribeiro, M.A., Marmo, D.B., Santos, C.I., Toro, A.A., Mendes, R.T., Cielo, F.M. and Ribeiro, J.D. (2010) Effects of swimming on spirometric parameters and bronchial hyperresponsiveness in children and adolescents with moderate persistent atopic asthma. Journal of Pediatrics, 86, 384-390. doi:10.2223/JPED.2022

[3] Matsumoto, I., Araki, H., Tsuda, K., Odajima, H., Nishima, S., Higaki, Y., Tanaka, H., Tanaka, M. and Shindo, M. (1999) Effects of swimming training on aerobic capacity and exercise induced bronchoconstriction in children with bronchial asthma. Thorax, 54, 196-201.

doi:10.1136/thx.54.3.196

[4] Font-Ribera, L., Villanueva, C.M., Nieuwenhuijsen, M.J., Zock, J.P., Kogevinas, M. and Henderson, J. (2011) Swimming pool attendance, asthma, allergies, and lung function in the Avon longitudinal study of parents and children cohort. American Journal of Respiratory and Critical Care Medicine, 183, 582-588.

doi:10.1164/rccm.201005-07610C

[5] Goodman, M. and Hays, S. (2008) Asthma and swimming: A meta-analysis. Journal of Asthma, 45, 639-647. doi:10.1080/02770900802165980

[6] Bemanian, M.H., Shirkhoda, S., Nakhjavani, M. and Mozafari, H. (2009) Effect of swimming on peak expiratory flow rate of atopic children. Iranian Journal of Allergy, Asthma and Immunology, 8, 121-123.

[7] Bar-Yishay, E., Gur, I., Inbar, O., Neuman, I., Dlin, R.A. and Godfrey, S. (1982) Differences between swimming and running as stimuli for exercise-induced asthma. European Journal of Applied Physiology, 48, 387-397. doi:10.1007/BF00430229

[8] Armour, J., Donnelly, P.M. and Bye, P.T. (1993) The large lungs of elite swimmers: An increased alveolar number? European Respiratory Journal, 6, 237-247.

[9] Cordain, L., Tucker, A., Moon, D. and Stager, J.M. (1990) Lung volumes and maximal respiratory pressures in collegiate swimmers and runners. Research Quarterly for Exercise \& Sport, 61, 70-74.

[10] Drobnic, F., et al. (1996) Assessment of chlorine exposure in swimmers during training. Medicine \& Science in Sports \& Exercise, 28, 271-274. doi:10.1097/00005768-199602000-00018

[11] Helenius, I., et al. (2002) Effect of continuing or finishing high-level sports on airway inflammation, bronchial hyperresponsiveness, and asthma: A 5-year prospective follow-up study of 42 highly trained swimmers. Journal of Allergy and Clinical Immunology, 109, 962-968.

[12] Bernard, A., et al. (2006) Chlorinated pool attendance, atopy, and the risk of asthma during childhood. Environmental Health Perspectives, 114, 1567-1573. doi:10.1289/ehp.8461

[13] Paivinen, M.K., Keskinen, K.L. and Tikkanen, H.O. (2010) Swimming and asthma: Factors underlying respiratory symptoms in competitive swimmers. The Clinical Respiratory Journal, 4, 97-103.

[14] Päivinen, M.K., Keskinen, K.L. and Tikkanen, H.O. (2013) Swimming and asthma: Differences between women and men. Journal of Allergy, 2013, Article ID: 520913. doi:10.1155/2013/520913

[15] Miller, M.R., Hankinson, J., Brusasco, V., Burgos, F., Casaburi, R., Coates, A., Crapo, R, Enright, P., van der Grinten, C.P., Gustafsson, P., Jensen, R., Johnson, D.C., MacIntyre, N., McKay, R., Navajas, D., Pedersen, O.F., Pellegrino, R., Viegi, G. and Wanger, J. (2005) ATS/ERS task force. Standardisation of spirometry. European Respiratory Journal, 26, 319-338. doi:10.1183/09031936.05.00034805 
[16] Viljanen, A.A., Halttunen, P.K., Kreus, K.-E. and Viljanen, B.C.(1982) Spirometric studies in non-smoking, healthy adults. Scandinavian Journal of Clinical and Laboratory Investigation, 42, 5-20.

[17] Koillinen, H., Vanne, O., Niemi, V. and Laakkonen, E. (1998) Terveiden suomalaisten lasten spirometrian ja uloshengityksen huippuvirtauksen viitearvot. Suomen Lääkärilehti, 39, 395-402.

[18] American Thoracic Society (1991) Lung function testing: Selection of reference values and interpretative strategies. American Review of Respiratory Disease, 144, 12021218. doi:10.1164/ajrccm/144.5.1202

[19] Pellegrino, R., Viegi, G., Brusasco, V., Crapo, R.O., Burgos, F., Casaburi, R., Coates, A., van der Grinten, C.P., Gustafsson, P., Hankinson, J., Jensen, R., Johnson, D.C., MacIntyre, N., McKay, R., Miller, M.R., Navajas, D., Pedersen, O.F. and Wanger, J (2005). Interpretative strategies for lung function tests. European Respiratory Journal, 26, 948-968. doi:10.1183/09031936.05.00035205

[20] Bernard, A., Carbonelle, S., Nickmilder, M. and de Burbure, C. (2005) Non-invasive biomarkers of pulmonary damage and inflammation: Application to children exposed to ozone and trichloramine. Toxicology and Applied Pharmacology, 206, 185-190. doi:10.1016/j.taap.2004.10.022

[21] Sandrini, A., et al. (2009) Fractional exhaled nitric oxide in asthma: An update. Respirology, 15, 57-70. doi:10.1111/j.1440-1843.2009.01616.x

[22] Hery, M., Gerber, J.M., Gendre, J.C., Hubert, G. and Rebuffaud, J. (1995) Exposure to chloroamines in the atmosphere of indoor swimming pools. Annals of Occupational Hygiene, 39, 427-439.

[23] Magel, J.R. and Faulkner, J.A. (1967) Maximum oxygen uptakes of college swimmers. Journal of Applied Physiology, 22, 929-933.

[24] Rundell, K.W., et al. (2001) Self-reported symptoms and exercise-induced asthma in the elite athlete. Medicine \& Science in Sports \& Exercise, 33, 208-213. doi:10.1097/00005768-200102000-00006

[25] Rundell, K.W., et al. (2000) Exercise-induced asthma screening of elite athletes: Field versus laboratory exercise challenge. Medicine \& Science in Sports \& Exercise, 32, 309-316. doi:10.1097/00005768-200002000-00010

[26] Parsons, J.P., et al. (2009) Management of exercise-induced bronchospasm in NCAA athletic programs. Medicine \& Science in Sports \& Exercise, 41, 737-741. doi:10.1249/MSS.0b013e31818d569d

[27] Parsons, J.P., et al. (2007) Prevalence of exercise-induced bronchospasm in a cohort of varsity college athletes. $\mathrm{Me}$ dicine \& Science in Sports \& Exercise, 39, 1487-1492. doi:10.1249/mss.0b013e3180986e45

[28] Morris, M.J., Schwartz, D.S., Nohrenberg, J.L. and Dooley, S.N. (2007) Airway hyper reactivity in asymptomatic military personnel. Military Medicine, 172, 1194-1197.

[29] Hull, J.H., et al. (2007) Exercise-induced bronchoconstriction in athletes-should we screen? Medicine \& Science in Sports \& Exercise, 39, 2117-2124. doi:10.1249/mss.0b013e3181578db2

[30] Mahler, D.A. (1993) Exercise-induced asthma. Medicine \& Science in Sports \& Exercise, 25, 554-561. doi:10.1249/00005768-199305000-00005

[31] Bonsignore, M.R., et al. (2003) Increased airway inflamematory cells in endurance athletes: What do they mean? Clinical \& Experimental Allergy, 33, 14-21. doi:10.1046/j.1365-2222.2003.01557.x 